\title{
A New Method of Flanges Extrusion in Hollow Products - Analysis of the Limiting Phenomena
}

\author{
Grzegorz Winiarski ${ }^{1 *}$, Tomasz Adam Bulzak', Łukasz Wójcik' ${ }^{1}$, Mirosław Szala' \\ 1 Mechanical Engineering Faculty, Lublin University of Technology, Nadbystrzycka 36, 20-618 Lublin, Poland \\ * Corresponding author's e-mail:g.winiarski@pollub.pl
}

\begin{abstract}
The paper presents an innovative method of metal forming of hollow flanged elements. In this process, flanges are formed using a movable sleeve, which moves in the opposite direction to the punch. The movement of the sleeve causes a closed impression to open, due to which the flange is also formed in a semi-free impression. The tube billets were made of the $42 \mathrm{CrMo} 4$ grade steel deformed under the cold metal forming conditions. The calculations were conducted using the finite elements method in Deform-2D/3D. Various technological parameters of the process were analysed, among others the diameter of the flange and the initial height of the impression of the movable sleeve. On the basis of the obtained results, the limiting phenomena of the process were determined and the influence of the analysed technological parameters on these phenomena were presented.
\end{abstract}

Keywords: extrusion, flanging, hollow parts, cold metal forming.

\section{INTRODUCTION}

Forming hollow elements with the method of metal forming is possible with the use of various technologies and semi-finished products. The billet is usually rods or tubes. In the case of rods it is necessary to make a hole, which results in high contact pressures transferred by the tools as well as material loss. In the case of the hole being machined, even greater material loss occurs and the production time is significantly longer. Therefore, using hollow billets seems to be a right alternative. Nevertheless, metal forming of hollow billets is connected to numerous limitations hindering or preventing the applicability of certain technologies. Due to this fact, new methods of effective manufacturing of hollow elements, usually dedicated for a certain type of forgings, are sought after. For example, the forgings of stepped shafts can be manufactured using a new method of rotational compression $[1,2]$. In this process, the workpiece is formed using three rolls which move in the radial direction and rotate simultaneously. Due to this fact, the material-tool contact surface is changeable, and therefore the workpiece does not cool down excessively, which enables the process to be conducted under hot working conditions. Despite numerous advantages, certain limitations to this process occur, mainly: deformation of the semi-finished product wall, material cracking, twisting of the formed steps, uncontrolled slip and deformation of the crosssection of the formed steps [3]. Another example of a new manufacturing method of stepped shafts from tube billets is cross-wedge rolling rail axles [4]. Apart from the stepped shafts, the elements of hydraulic installations are also manufactured directly from the tube billets. Seeking new metal forming methods focuses on developing the technology of hole flanging in order to produce branched tubings $[5,6]$. In the cases where it is necessary to connect a tube with a flange, e.g. made of sheet metal, the research on innovative technological solutions is conducted as well. The methods of connecting based on upsetting and/or flanging, where the moving tool is only the punch or upper die [7] are modified in such a way that moving bottom containers/bottom dies $[8 \div 10]$ 
are used additionally, which increases the effectiveness of the process. Moving or allowing the movement of several tools is also performed in the new flanging processes. The new method of radial extrusion of flanges uses a limit ring as a moving tool. This ring deforms during the process, which allows to obtain flanges with relatively large diameters [11]. The process presented in the study [12] is realised with top and bottom dies simultaneously moving and creating a closed impression of a fixed height. In the works $[13,14]$ using the movable counter punch increases the height of the closed impression, which allows one to produce a flange with relatively significant heights in relation to the wall thickness of the tube billet. In the technologies based on extrusion with a movable sleeve, moving spontaneously as a result of pressure force of the deformed material [15] or powered independently from the punch $[16,17]$ the volume of the closed impression increases along with the stage of the process. This phenomenon eliminates local buckling and folding, due to which it is possible to obtain flanges of the heights difficult to obtain with conventional methods.

On the basis of the analysis of literature on metal forming hollow elements directly from tube billets, it was stated that the research on new technologies is continuously being carried out. Considering the advantages resulting from the extrusion of flanges using several movable tools it was deemed favourable to continue the research on this subject. Due to this fact, a new process of extrusion with a movable sleeve, in which the forging is formed in a semi-free impression was developed. The objective of research was to theoretically verify the proposed method and analyse the influence of the basic parameters of the process, that is the diameter of the extruded flange and the initial height of the impression in relation to the occurrence of the limiting phenomena.

\section{RESEARCH METHODOLOGY}

The scheme of the new process was presented in Figure 1. A fragment of the billet with the length $1_{\mathrm{s}}$, being the shank part of the forging, is located in the bottom die. During the process, this fragment is not subjected to plastic strain, since it is located in the closed impression. This impression is created between the ejector, mandrel and the aforementioned die and its volume is similar to the volume of the material inside. The remaining part of the billet with the length $l_{f}$, transformed into the flange part of the forging as a result of the plastic strain, is located in the movable sleeve. Initially, the sleeve adheres to the bottom die creating an impression with the temporary height $h_{0}$ and diameter $\mathrm{D}_{\mathrm{f}}$ After filling, the sleeve is set in motion. Due to this fact, the closed impression is opened and the flange with a progressively greater height is formed in a semi-free impression. The main advantage of this method is the fact that during the forming process, the deformed material in the forming area is only partially in the closed impression. For this reason the friction forces on the contact surface of movable sleeve - deformed material decrease, which positively influences both the load on the punch and the sleeve. Additionally, the material does not move in relation to the bottom die in the shank part of the forging; therefore, the friction forces on the surface of the impression of the tool influence the process of flange extrusion to an insignificant degree.

The numerical analysis of the discussed technology was performed with the finite elements method in Deform-2D/3D. The calculations were performed under cold working conditions, assuming axial-symmetric strain state. Tubular billets made of $42 \mathrm{CrMo} 4$ steel were used. The material flow curve for this steel was described using the Hollomon model (1). The material constants occurring in the equation were determined in own research in upsetting test of spheroidized cylindrical samples.

$$
\sigma_{p}=1023 \cdot \varepsilon^{0.2}
$$

where: $\sigma_{p}$ - true stress, $\varepsilon-$ true strain.

The conditions of the billet-tool contact were described by a shear friction model assuming the friction factor equal $m=0.3$. The initial temperature of the objects was $20^{\circ} \mathrm{C}$, whereas the heat transfer coefficient equalled $10 \mathrm{~kW} / \mathrm{m}^{2} \mathrm{~K}$. The speed of the punch $v_{p}$ and mandrel $v_{m}$ was similar and equal $100 \mathrm{~mm} / \mathrm{min}$. The speed of the movable sleeve was determined on the basis of the constancy-of-volume relationship described with the equation (2). The kinematics of the tools indicates that in time $d t$, the punch moves at the speed $v_{p}$, whereas the movable sleeve at $v_{s}$ In accordance with this, the speed of the movable sleeve determined from the equation (2) is expressed by the dependency (3). 


$$
\begin{gathered}
\frac{\pi}{4} \cdot\left(D^{2}-d^{2}\right) \cdot v_{p} \cdot d t=\frac{\pi}{4} \cdot\left(D_{f}^{2}-D^{2}\right) \cdot v_{s} \cdot d t \\
v_{s}=v_{p} \cdot \frac{D^{2}-d^{2}}{D_{f}^{2}-D^{2}}
\end{gathered}
$$

In the calculations, different values of the diameter of the extruded flange $\mathrm{D}_{\mathrm{f}}$ and the initial height of the impression $h_{0}$ were investigated. The list of the analysed cases is presented in Table 1 . First of all, the initial phase of the process, consisting of filling the impression with the initial height $\mathrm{h}_{0}$ by the deformed material, was analysed. This stage was realised assuming that the compressive stress in the punch cannot exceed $2100 \mathrm{MPa}$, which is safe for the tool materials dedicated for

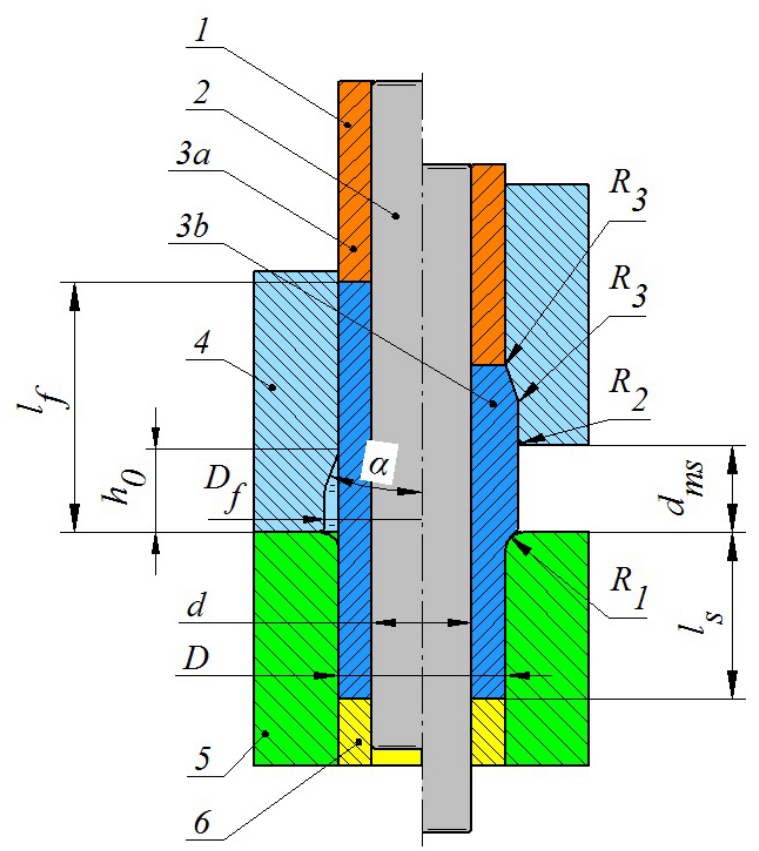

Fig. 1. Scheme of the process of extrusion with a movable sleeve in a semi-free impression;

1 - punch, 2 - mandrel, $3 \mathrm{a}$ - billet, $3 \mathrm{~b}$ - forging,

4 - movable sleeve, 5 - bottom die, 6 - ejector

Table 1. Analysed technological parameters of the process of extrusion with a movable sleeve in a semifree impression (markings compliant with Fig. 1)

\begin{tabular}{|c|c|c|c|c|}
\hline $\begin{array}{c}\mathrm{d} \\
{[\mathrm{mm}]}\end{array}$ & $\begin{array}{c}\mathrm{D} \\
{[\mathrm{mm}]}\end{array}$ & $\begin{array}{c}\mathrm{I}_{\mathrm{s}} \\
{[\mathrm{mm}]}\end{array}$ & $\begin{array}{c}\mathrm{R}_{1} \\
{[\mathrm{~mm}]}\end{array}$ & $\begin{array}{c}\mathrm{R}_{2} \\
{[\mathrm{~mm}]}\end{array}$ \\
\hline 30 & 50 & 50 & 5 & 2 \\
\hline $\begin{array}{c}\mathrm{R}_{3} \\
{[\mathrm{~mm}]}\end{array}$ & $\begin{array}{c}\alpha \\
{\left[{ }^{\circ}\right]}\end{array}$ & $\begin{array}{c}\mathrm{D}_{\mathrm{f}} \\
{[\mathrm{mm}]}\end{array}$ & $\begin{array}{c}\mathrm{h}_{0} \\
{[\mathrm{~mm}]}\end{array}$ & $\begin{array}{c}\mathrm{I}_{\mathrm{f}} \\
{[\mathrm{mm}]}\end{array}$ \\
\hline 5 & 20 & $54,56,58$ & $\begin{array}{c}14,16, \\
18,20, \\
22,24\end{array}$ & 75 \\
\hline & & & & \\
\hline
\end{tabular}

cold working processes. For the selected conditions of the process, that is $\mathrm{D}_{\mathrm{f}}$ and $\mathrm{h}_{0}$ at which the initial phase of the process progresses correctly, a second stage of tests was conducted, in which the movable sleeve moves in the opposite direction of the movement of the punch. This results in an increase of the height of the flange.

\section{ANALYSIS OF THE RESULTS}

The test results indicated that at the initial stage of the extrusion process, where the closed impression with height $h_{0}$ is filled with the deformable material, limiting phenomena occur and prevent the correct progression of the process. The main cause is the limited mechanical strength of the punch. The most commonly used limitation is underfilling the impression in the hole of the forging (limiting phenomenon LP-1 presented in Fig. 2). This defect occurs due to a local buckling of the billet wall, as a result of which the material flows away from the mandrel and comes in contact with the wall of the impression with the diameter $\mathrm{D}_{\mathrm{f}}$ first. Upon achieving this contact, the material flow outside is hindered and intensive upsetting of the wall occurs, which causes the material to flow in the direction of the axis symmetry of the forging. However, due to the size and the allowed load on the punch, the underfilling cannot be eliminated in every case, which causes the defect to occur at the initial stage of the process.

In order to determine the influence of each parameter of the process on the possibility of defect the occurrence, the measurement of the underfilling in the radial and axial directions was performed $\left(\Delta \mathrm{x}_{\mathrm{i}}\right.$ and $\Delta \mathrm{y}_{\mathrm{i}}$ in Fig. 2). On the basis of the obtained results and dependencies (4) and (5) the maximum underfilling values $\Delta \mathrm{x}_{\max }$ and $\Delta \mathrm{y}_{\max }$, were determined. Their quotient in the function of the initial height of the impression $h_{0}$ and the diameter of the flange was presented in Fig. 3 and 4. The smaller the value of the ratio $\Delta \mathrm{x}_{\max } / \Delta \mathrm{y}_{\max }$, the smaller the underfilling. The ratio equal to 0 means that the defect did not occur. The data presented in Figure 3 indicate that the increase of the initial height of the impression independently from the diameter of the flange caused a progressively greater underfilling of the impression. The safe values of the initial height of the impression are 16 and $18 \mathrm{~mm}$ for the flanges with the diameter 54 and $56,58 \mathrm{~mm}$, respectively. 

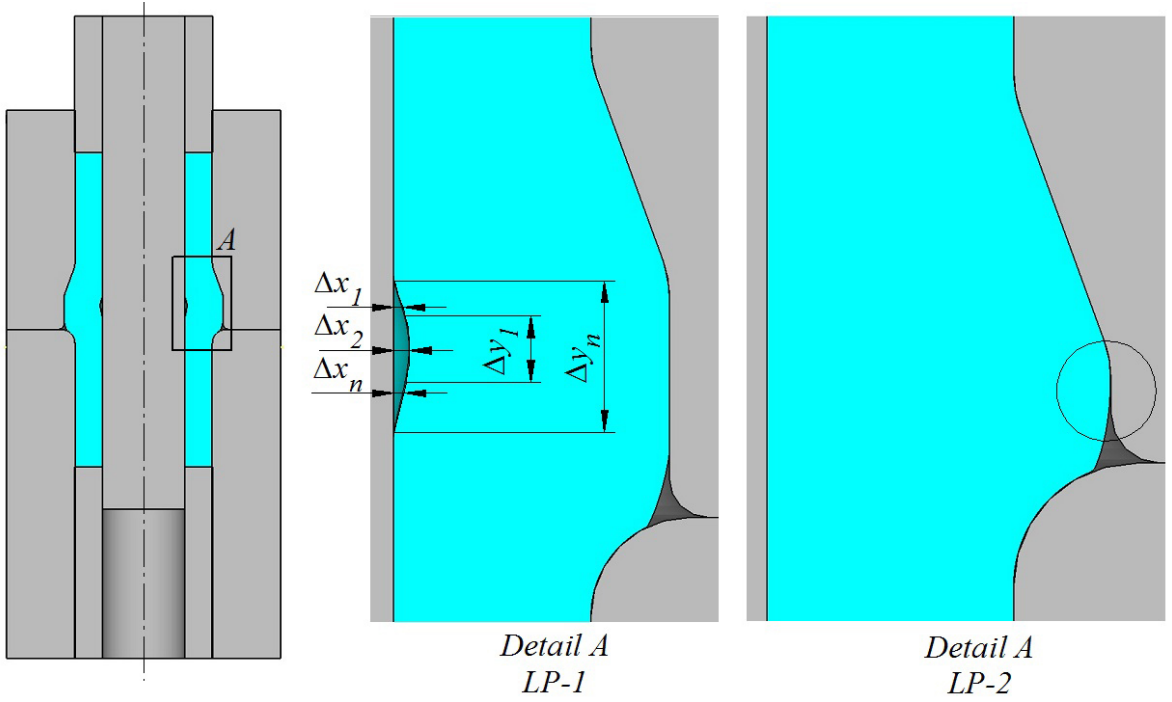

Fig. 2. Limiting phenomena in the initial phase of flange forming by extrusion with a movable sleeve in a semi-free impression

Figure 4 presents the data on the influence of the diameter of the flange on the underfilling. It was observed that at the same initial heights of the impression, the underfilling described with the relation $\Delta \mathrm{x}_{\max } / \Delta \mathrm{y}_{\max }$ increases along with the diameter of the flange. This is caused by the fact that at a greater diameter of the flange, the deformed material flows in the radial direction, moving away from the axis of the forging.

Another limiting phenomenon, observed only in a singlecase, was underfilling of the cylindrical impression with diameter $\mathrm{D}_{\mathrm{f}}$ (limiting phenomenon LP-2 shown in Figure 2). It occurs when the initial height of the impression $h_{0}$ is too small. In this case, local buckling of the billet wall does not occur and therefore the material remains in contact with the mandrel. Filling of the impression is caused by upsetting of the wall and material flowing radially. The small height of the impression $h_{0}$ causes total filling of the impression to require the application of the total force higher than the mechanical strength of the punch.

The list of the limiting phenomena in relation to all of the analysed cases was presented in Table 2. In the case of extrusion a flange with the diameters $\mathrm{D}_{\mathrm{f}}=56$ and $58 \mathrm{~mm}$ and the initial height of the impression equal, respectively, $\mathrm{h}_{0}=14$ and $18 \mathrm{~mm}$ none of the limiting phenomena listed above were observed. Nevertheless, the impression is filled correctly when the force acting on the punch reaches a value close to the maximum. Due to this fact, these are boundary

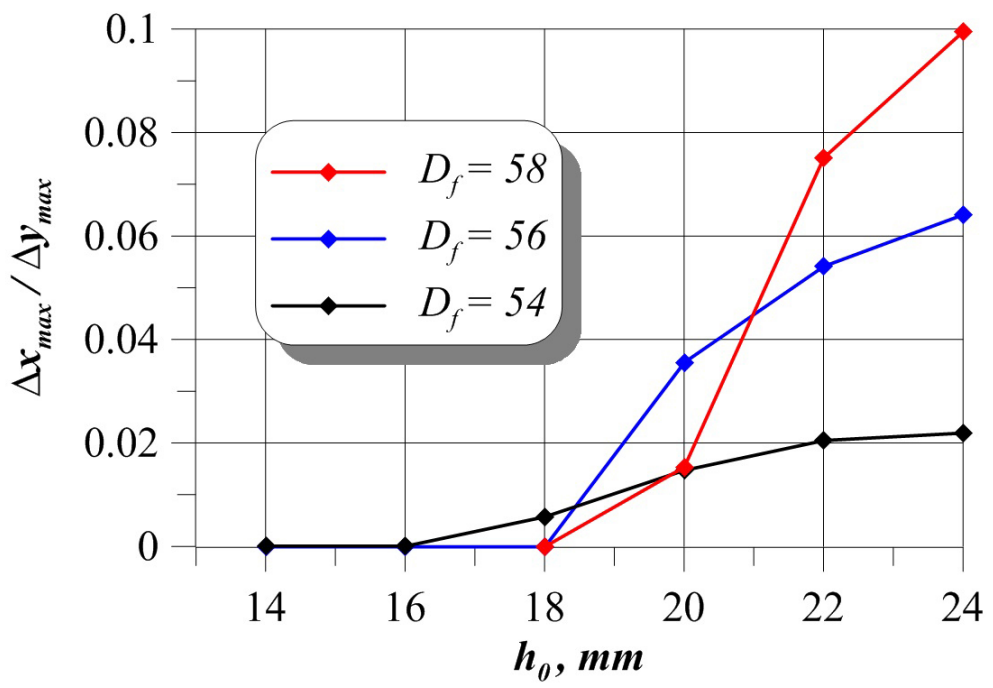

Fig.3. Size of the underfilling of the impression in a function of its initial height $\mathrm{h}_{0}$ 


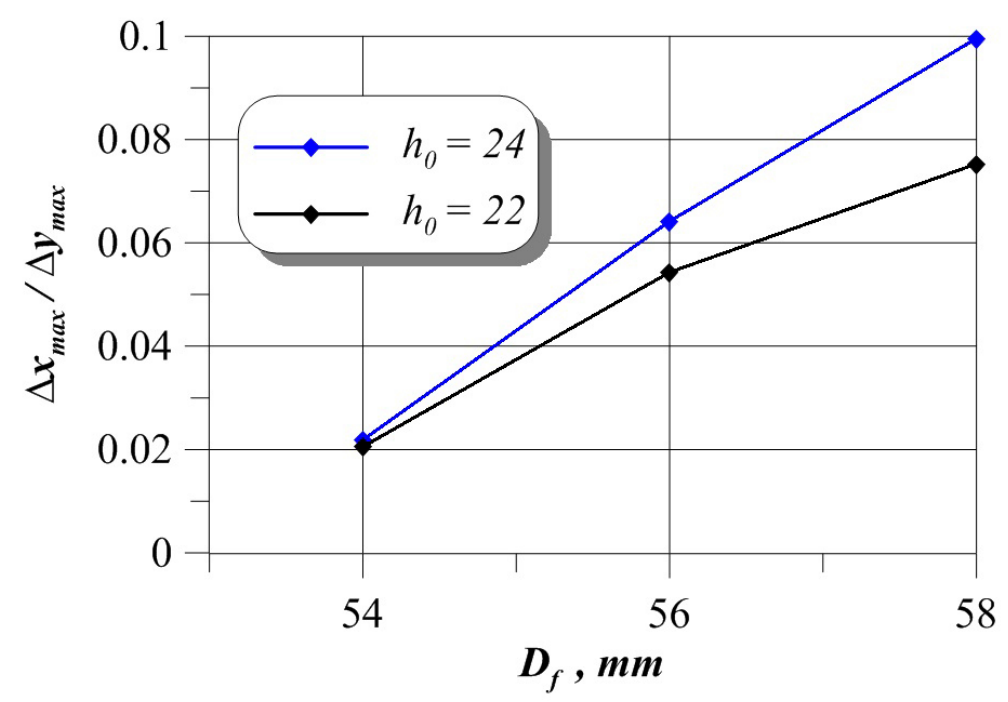

Fig. 4. Size of underfilling of the impression in the function of the diameter $D_{f}$ of the flange

cases due to the mechanical strength of the tools, which, as mentioned above, influences the occurrence of the limiting phenomena. The best results in relation to the initial stage of the process were obtained in the case of extrusion defined with the following parameters: : $\mathrm{D}_{\mathrm{f}}=54 \mathrm{~mm}, \mathrm{~h}_{0}=14$ and $16 \mathrm{~mm}$ and $\mathrm{D}_{\mathrm{f}}=56 \mathrm{~mm}, \mathrm{~h}_{0}=16$ and $18 \mathrm{~mm}$. A correct filling of the impression was obtained at significantly lower values of forces acting on a punch.

$$
\begin{aligned}
\Delta x_{\max } & =\max \left\{\Delta x_{1}, \Delta x_{2}, \Delta x_{3}, \ldots, \Delta x_{n}\right\} \\
\Delta y_{\max } & =\max \left\{\Delta y_{1}, \Delta y_{2}, \Delta y_{3}, \ldots, \Delta y_{n}\right\}
\end{aligned}
$$

In the case of the four abovementioned technological variants of the process, a second stage of the research was conducted, where the subject of analysis was the phase of the process in which the sleeve moves in the opposite direction to the punch (Fig. 5). Due to this fact, a flange with a progressively greater height is obtained, which

Table 2. Limiting phenomena in the initial phase of the extrusion process depending on the technological parameters

\begin{tabular}{|c|c|c|c|}
\hline \multirow{2}{*}{$\mathrm{h}_{0}[\mathrm{~mm}]$} & \multicolumn{3}{|c|}{$\mathrm{D}_{\mathrm{f}}[\mathrm{mm}]$} \\
\cline { 2 - 4 } & 54 & 56 & 58 \\
\hline 14 & correct & max. punch load & not investigated \\
\hline 16 & correct & correct & LP-2 \\
\hline 18 & LP-1 & correct & max. punch load \\
\hline 20 & LP-1 & LP-1 & LP-1 \\
\hline 22 & LP-1 & LP-1 & LP-1 \\
\hline 24 & LP-1 & LP-1 & LP-1 \\
\hline
\end{tabular}

is formed in the semi-free impression. It was observed that during extrusion, an unintentional increase of the inner diameter of the forging in the flange area occurs along with the displacement $\mathrm{d}_{\mathrm{ms}}$ of the movable sleeve. This can be accompanied by an uneven increase of the thickness of the billet wall throughout the entire height of the flange. Both of these phenomena are caused by the fact that the extrusion is performed in a semifree impression; therefore, the material flow is not limited in every area. Both the increase of the inner diameter and the wall thickness depend on the value of displacement of the movable sleeve. The volume of the material in a closed impression decreases along with an increase in the displacement of the movable sleeve, which significantly influences the occurrence of the limiting phenomena.

In order to conduct a quantitative assessment, two parameters described with the dependencies (6) and (7) were introduced, mainly the mean wall thickness $g_{r}$ in the flange area related to the assumed thickness (estimated on the basis of the dimensions of the impressions of the tools) and mean increase of the inner diameter $\Delta \mathrm{x}_{\mathrm{m}}$ also related to the assumed diameter (equal the diameter of the mandrel). The values of $g_{r}$ and $\Delta x_{m}$ were determined for various locations $\mathrm{d}_{\mathrm{ms}}$ of the movable sleeve on the basis of the measurements of the inner and outer diameter of the forging in the flange area, according to the scheme shown in Fig. 5a. The obtained results were presented in Fig. 6 and 7 in a diagram form.

On the basis of the analysis of the curves progression on the mean increase of the inner diameter of the forging $\Delta \mathrm{x}_{\mathrm{m}}$ (Fig. 6) it can be stated 


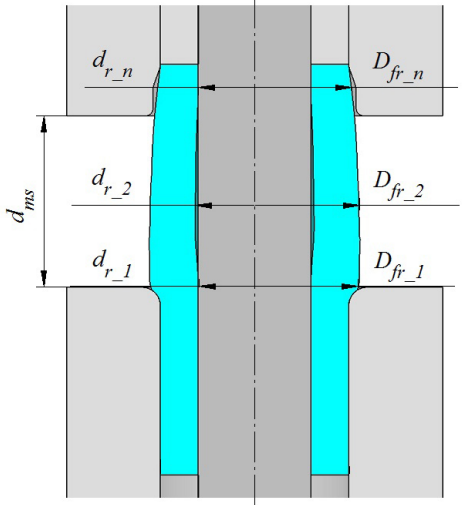

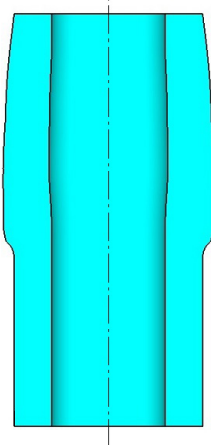

b)

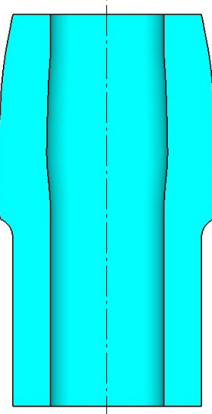

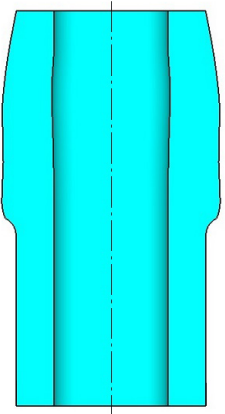

d)

Fig. 5. Forgings obtained in the process of extrusion with a movable sleeve in a semi-free impression: a) $\left.\left.\mathrm{D}_{\mathrm{f}}=54 \mathrm{~mm}, \mathrm{~h}_{0}=14 \mathrm{~mm}, \mathrm{~b}\right) \mathrm{D}_{\mathrm{f}}=54 \mathrm{~mm}, \mathrm{~h}_{0}=16 \mathrm{~mm}, \mathrm{c}\right) \mathrm{D}_{\mathrm{f}}=56 \mathrm{~mm}, \mathrm{~h}_{0}=16 \mathrm{~mm}$, d) $\mathrm{D}_{\mathrm{f}}=56 \mathrm{~mm}, \mathrm{~h}_{0}=18 \mathrm{~mm}$

that an increase of the mean inner diameter of the forging occurs along with the increase of displacement $\mathrm{d}_{\mathrm{ms}}$ of the movable sleeve, indicating the material progressively moving away from the mandrel. This phenomenon has the least influence on the progression of the extrusion process of a flange with the diameter $\mathrm{D}_{\mathrm{f}}=56 \mathrm{~mm}$ using the impression of the initial height $h_{0}=18 \mathrm{~mm}$. In this case, the increase of the inner diameter is very low regarding the value of displacement of the movable sleeve equalling $\mathrm{d}_{\mathrm{ms}}=20 \mathrm{~mm}$. In the further phase of the process, an increase of the discussed parameter can be noticed, with the maximum value reaching $1.9 \%$. In the remaining cases the limitation is more visible and can be clearly noticed at smaller values of the displacement of the movable sleeve. It is also to be noted that the $\Delta \mathrm{x}_{\mathrm{m}}$ parameter is significantly influenced by the initial height of the impression $\mathrm{h}_{0}$ It is particularly visible during the extrusion of a flange with a diameter $\mathrm{D}_{\mathrm{f}}=56 \mathrm{~mm}$. It can therefore be stated that a greater height of the impression $h_{0}$ decreases the mean increase of the inner diameter $\Delta \mathrm{x}_{\mathrm{m}}$ of the forging.

On the basis of the analysis of the $\Delta \mathrm{x}_{\mathrm{m}}$ parameter for the flange diameter $\mathrm{D}_{\mathrm{f}}=54$ and $56 \mathrm{~mm}$, two extrusion cases were selected for which mean wall thickness $g_{r}$ in the flange area was analysed. On the basis of this analysis (Fig. 7) it was stated that in the initial phase of the movement of the movable sleeve, the wall thickness is insignificantly smaller than the assumed value. This indicates that the material in the area of the movable sleeve does not fully fill its impression, which decreases the value of the mean thickness. In the further part of the process, the mean wall thickness increases, reaching the values greater than expected. This is caused by the fact that in the flange area located outside the impression of movable sleeve, the wall thickness is greater than assumed, since an excessive upsetting of the material in the free area occurs. When the process

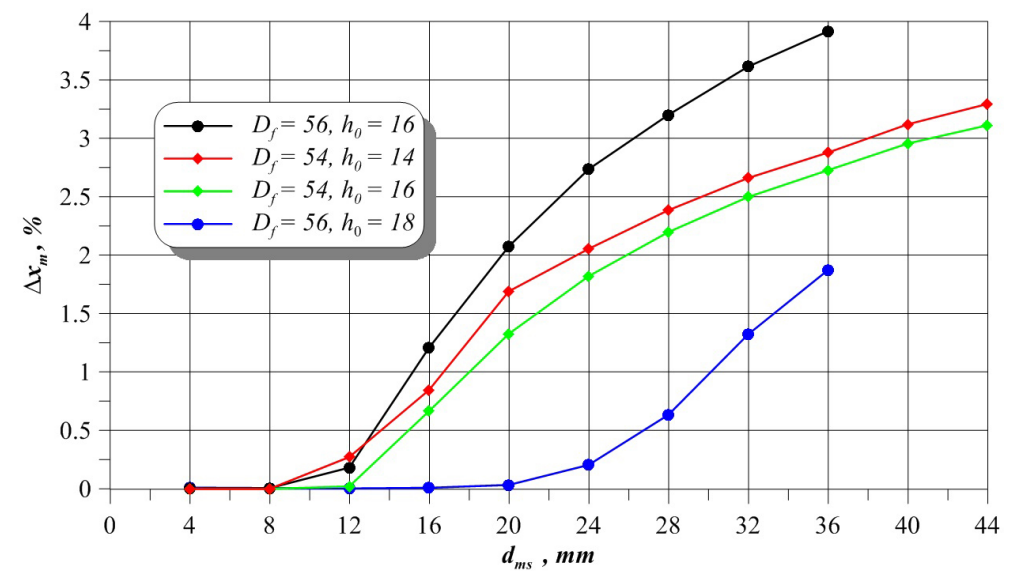

Fig. 6. Mean increase of the inner diameter $\Delta x_{m}$ of the forging in the flange area as a function of displacement $d_{m s}$ of the movable sleeve 


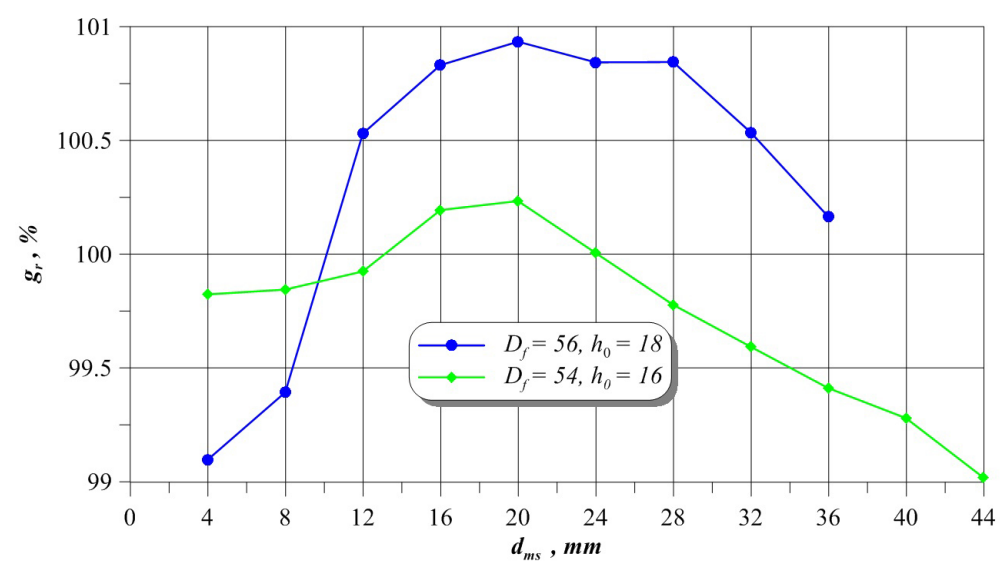

Fig. 7. Mean wall thickness $g_{r}$ of the forging in the flange area as a function of displacement $\mathrm{d}_{\mathrm{ms}}$ of the movable sleeve

is $50 \%$ complete, a visible drop in the mean wall thickness can be observed, which is connected with the fact that the flange in the free area is subjected to upsetting to a lesser degree, and more to the material moving away from the mandrel (see Fig. 6). It is however to be observed that the discussed changes to the mean wall thickness are in a small range of about $\pm 1 \%$ in relation to the assumed value. Apart form a significant influence of the displacement of the movable sleeve on the wall thickness, it can be observed that the initial height of the impression $\mathrm{h}_{0}$ has a certain influence as well. At greater values of $h_{0}$, greater increases of the wall thickness can be observed, which is caused by a less significant material moving away from the mandrel.

$$
\begin{gathered}
g_{r}=100 \% \cdot \frac{1}{n} \cdot \sum_{i=1}^{i=n}\left(\frac{D_{f r_{-} i}-d_{r_{-} i}}{D_{f}-d}\right) \\
\Delta x_{m}=100 \% \cdot \frac{1}{n} \cdot \sum_{i=1}^{i=n}\left(\frac{d_{r_{-} i}-d}{d}\right)
\end{gathered}
$$

\section{CONCLUSIONS}

On the basis of the research, the following conclusions were drawn:

- it is possible to form flanges in hollow elements using the method of extrusion with a movable sleeve in a semi-free impression,

- at the initial stage of the process, in which the sleeve does not move, the limiting phenomena resulting from a limited mechanical strength of the punch were observed; as a result, such defects as underfilling of the impression in the hole of the forging or in the outer area of the surface of the flange can occur,

- at a further stage of the process, in which the sleeve moves in the opposite direction to the punch, two limiting phenomena occur: unintended increase of the inner diameter of the forging and irregular increase of the wall thickness in the flange area,

- each of those limiting phenomena depend on the technological parameters of the process; at the initial stage, the key parameters are the diameter of the extruded flange and the initial height of the impression, whereas during extrusion with a movable sleeve, the quality of the forging is also influenced by the value of displacement of the sleeve.

\section{Acknowledgement}

The research was financed in the framework of the project: New metal forming technique for producing flanged hollow parts for the mining industry, No. LIDER/1/0003/L-9/17/NCBR/2018. Total cost of the Project: 1197000 PLN. The project is financed by the National Centre for Research and Development under the 9th edition of the LIDER Programme.

\section{REFERENCES}

1. Tomczak J. and Pater Z. Analysis of metal forming process of a hollowed gear shaft. Metalurgija, 51(4), 2012, 497-500.

2. Pater Z., Gontarz A., Tomczak J. and Bulzak T. Producing hollow drive shafts by rotary compression. Archives of Civil and Mechanical Engineering, 15(4), 2015, 917-924. 
3. Bartnicki J., Tomczak J. and Pater Z. Limits of the process of rotational compression of hollow stepped shafts. Materials, 12(18), 2019, 1-15.

4. Pater Z., Lis K. and Walczuk-Gagała P. Numerical analysis of the cross-wedge of a hollow rail axle. Advances in Science and Technology Research Journal, 14(1), 2020, 145-153.

5. Teramae T., Manabe K., Ueno K., Nakamura K. and Takeda H. Effect of material properties on deformation behavior in incremental tube-burring process using a bar tool. Journal of Materials Processing Technology, 191(1-3), 2007, 24-29.

6. Yang C., Wen T., Liu L.T., Zhang S. and Wang H. Dieless incremental hole-flanging of thin-walled tube for producing branched tubing. Journal of Materials Processing Technology, 214(11), 2014, 2461-2467.

7. Alves L.M, Gameiro J., Silva C.M.A. and Martins P.A.F. Sheet-bulk forming of tubes for joining applications. Journal of Materials Processing Technology, 240, 2017, 154-161.

8. Alves L.M., Afonso R.M., Silva C.M.A. and Martins P.A.F. Joining tubes to sheets by boss forming and upsetting. Journal of Materials Processing Technology, 252, 2018, 773-781.

9. Alves L.M., Afonso R.M., Silva C.M.A. and Martins P.A.F. Joining by sheet-bulk forming of tubes to sheets. Procedia Manufacturing, 15, 2018, 1322-1329.

10. Afonso R.M., Alves L.M. and Martins P.A.F. Joining by boss forming of rods and tubes to sheets. Journal of Advanced Joining Processes, 1, 2020, 100001 .
11. Winiarski G., Gontarz A. and Samołyk G. Flange formation in aluminium alloy EN AW 6060 tubes by radial extrusion with the use of a limit ring. Archives of Civil and Mechanical Engineering, 19(4), 2019, 1020-1028.

12. Alves L.M., Afonso R.M., Silva C.M.A. and Martins P.A.F. Boss forming of annular flanges in thin-walled tubes. Journal of Materials Processing Technology, 250, 2017, 182-189.

13. Zhu S., Zhuang X., Zhu Y. and Zhao Z. Thickening of cup sidewall through sheet-bulk forming with controllable deformation zone. Journal of Materials Processing Technology, 262, 2018, 597-604.

14. Zhu S., Zhuang X., Xu D., Zhu Y. and Zhao $Z$. Flange forming at an arbitrary tube location through upsetting with a controllable deformation zone. Journal of Materials Processing Technology, 273, 2019, 116230.

15. Winiarski G. and Gontarz A. Numerical and experimental study of producing two-step flanges by extrusion with a movable sleeve. Archives of Metallurgy and Materials, 62(2), 2017, 495-499.

16. Winiarski G., Bulzak T., Wójcik Ł. and Szala M. Effect of tool kinematics on tube flanging by extrusion with a moving sleeve. Advances in Science and Technology Research Journal, 13(3), 2019, 210-216.

17. Winiarski G., Bulzak T., Wójcik Ł. and Szala M. Numerical analysis of a six stage forging process for producing hollow flanged parts from tubular blanks. Advances in Science and Technology Research Journal, 14(1), 2020, 201-208. 